\title{
Auditory discrimination of tone-pulse onsets
}

\author{
JACEK SMURZYŃSKI and ADRIANUS J. M. HOUTSMA \\ Institute for Perception Research, Eindhoven, The Netherlands
}

\begin{abstract}
Two experiments are reported in which difference limens (DLs) were measured for onset times of a $1000-\mathrm{Hz}$ tone pulse. An adaptive two-alternative forced-choice procedure and (mostly) welltrained subjects were used. In the first experiment, DLs were measured for the rise time of linear onset ramps at rise-time values between 10 and $60 \mathrm{msec}$. The DLs follow Weber's law up to a rise time of about $50 \mathrm{msec}$, and do not support the notion that rise times are perceived in a categorical manner. In the second experiment, DLs were obtained for linear, exponential, and raisedcosine onset envelopes at rise-time values between 10 and $40 \mathrm{msec}$. When energy differences in the critical band around $1000 \mathrm{~Hz}$ are computed for just-discriminable onsets, values between $0.7 \mathrm{~dB}$ (10-msec rise time) and $0.3 \mathrm{~dB}$ (40-sec rise time) are found. These equivalent intensity DLs show the same "near miss to Weber's law" behavior as do intensity DLs for pure tones.
\end{abstract}

Recognition of a musical instrument by its sound is based on quasi-stationary attributes such as tone spectrum, as well as on transient attributes such as tone attack and decay. It has been shown (Berger, 1964; Clark, Luce, Abrams, Schlossberg, \& Rome, 1964; Saldanha \& Corso, 1964) that subjects' abilities to identify musical instruments correctly by their sound decreases significantly when sounds are presented without attack.

Further insight into the perceptual role of a tone attack was obtained through studies of differential sensitivity for a tone's onset time. A central question in these studies was whether a tone's rise (onset, attack) time forms a perceptual continuum in which, for instance, Weber's law would hold, or whether the physical onset-time continuum maps perceptually into a small number of subjective categories, resulting in so-called categorical perception. Especially during the last few years, there has been a renewed interest in categorical perception for nonspeech signals. Rosen and Howell (1981) determined that categorical discrimination functions could not be obtained for music-like stimuli spaced with equal intervals of the rise time, as had been reported by Cutting and Rosner (1974). Their subject's responses appeared rather to follow Weber's law; that is, difference limens (DLs) for rise time increased proportionally with increasing rise-time durations. These findings were confirmed by Kewley-Port and Pisoni (1984).

Smurzyński (1985) investigated subjects' abilities to identify stimuli solely on the basis of rise time. He found

\footnotetext{
The authors are indebted to Andrzej Rakowski for having stimulated this research. The invaluable and patient assistance of subjects Leszek Kaminiski, Teresa Rosciszewska, Mikolaj Wierusz, and Hannie van der Westen is gratefully acknowledged. This research was made possible by a grant from the Polish Academy of Sciences (Grant CPBP 02.03) and by a postdoctoral fellowship grant of Eindhoven University of Technology. Jacek Smurzyński's permanent address is Warsaw Academy of Music, Warsaw, Poland. Correspondence concerning this article and requests for reprints should be addressed to Adrianus J.M. Houtsma, Institute for Perception Research, P.O. Box 513, 5600 MB Eindhoven, The Netherlands.
}

that subjects trained in auditory perception, when presented with $300-\mathrm{Hz}$ sawtooth-wave bursts with six different rise times between 10 and $60 \mathrm{msec}$, generated typical confusion matrices with responses clustered around the main diagonal, rather than two sharply defined response categories ("pluck" and "bow"), as Cutting and Rosner (1974) had found. Further analysis of these identification data revealed that average received (or mutual) information (Garner \& Hake, 1951) in that experiment amounted to 1.3 bits. This is significantly more than the prediction of a categorical perception model that divides the 10 - to 60 -msec rise-time range into two perceptual categories, thereby limiting information transfer to $1 \mathrm{bit}$. Moreover, if Smurzyński's identification data are interpreted with a Thurstonian decision model (Braida \& Durlach, 1972; Durlach \& Braida, 1969), an average sensitivity $d^{\prime}$ of 2.9 is found between stimuli of successive rise times (i.e., 10 vs. $20 \mathrm{msec}, 20$ vs. $30 \mathrm{msec}$, etc.).

One of the criteria of categorical perception states that discrimination is constrained by identification. According to Kewley-Port and Pisoni (1984), the Weber fraction for rise time $T$ for $300-\mathrm{Hz}$ sawtooth stimuli, measured with an adaptive discrimination procedure and expressed as $\Delta T / T$, is around 0.8 for $T=10 \mathrm{msec}, 0.4$ for $T=20 \mathrm{msec}$, and 0.2 for rise times in the 30 - to 60 msec range. These results imply a sensitivity $d^{\prime}$ of about 1.0 for stimulus pairs that were quite comparable to the ones used in Smurzyński's (1985) identification experiment, which, however, yielded a much larger average $d^{\prime}$. This is not inconsistent only with the above-mentioned notion that discrimination is bounded by identification. It is equally inconsistent with the intuitive idea that simple discrimination of two stimuli should be easier than absolute identification of six stimuli because of the added memory noise involved in most absolute identification tasks. An explanation of this apparent discrepancy may be found in the fact that Smurzyniski worked with highly trained subjects, whereas Kewley-Port and Pisoni used mostly untrained subjects. This difference under- 
scores the need to perform both discrimination and identification experiments under comparable laboratory conditions and with the same (trained) subjects.

Other experiments on differential thresholds for rise time were performed by Van Heuven and Van den Broecke (1979) for $1000-\mathrm{Hz}$ pure-tone and white-noise bursts, and by Van den Broecke and Van Heuven (1983) for sawtooth, triangle, sine-wave, and white-noise bursts. They used the method of adjustment. Some of their results were in agreement with Weber's law. In other cases, rather constant absolute values of DLs for rise time were obtained. None of their data, however, showed a significant discontinuity in the DL function, as is expected with categorical perception.

In the present study, two experiments were conducted that were designed to improve our understanding of auditory discrimination of the rise time of pure-tone bursts. Experiment 1 was a replication of the Kewley-Port and Pisoni (1984) experiment, except that highly experienced subjects took part and only pure tones were used. The experiment was executed at the Warsaw Academy of Music. Experiment 2, performed at the Institute for Perception Research in Eindhoven, was based on subjects' reports of different discrimination cues being used in different regions of the rise-time continuum. At long rise times one seemed to perceive rise-time intervals as such, whereas at short rise times (shorter than 30 to $40 \mathrm{msec}$ ) one perceived the relative amplitude of a "thump" at the beginning of the sound. The possible role of cues based on energy splatter for short onset times was investigated by using three different types of onset functions. The specific question was whether onset discrimination varies with the onset function itself, or whether it depends simply on the resulting amount of energy spread during the onset, regardless of the shape of the onset function.

\section{EXPERIMENT 1}

\section{Method}

Stimuli. Stimuli consisted of $1000-\mathrm{Hz}$ pure-tone bursts with a linear rise (attack) starting on a positive zero crossing, a steadystate portion, and a 40 -msec linear decay. The overall length of the stimuli was $256 \mathrm{msec}$. Thus, the length of the steady state covaried with the duration of the onset ramp. Six stimuli with rise times of $10,20,30,40,50$, and $60 \mathrm{msec}$ were used as base stimuli to measure DLs. Rise time is defined as the time needed for the amplitude of the signal to reach its full steady-state level.

Amplitude envelopes of stimuli were generated digitally on an Olivetti M-20 microcomputer and stored in memory. They were output under computer control at a sample rate of $5 \mathrm{kHz}$, using a 10-bit multiplying digital-to-analog (D/A) converter, which multiplied the envelope by a $1000-\mathrm{Hz}$ sine wave (Hewlett Packard 3312 function generator). Stimuli were presented binaurally through TDH39 headphones at $70 \mathrm{~dB}$ SPL in a quiet testing room.

Procedure. Using an adaptive two-interval (two down, one up) forced-choice procedure without feedback, the subjects were asked to indicate which item of each pair of stimuli had the "more gradual onset." For each run of the tracking procedure, a single base stimulus was selected. The rise time difference of the initial pair was chosen to be about four times the DL estimated by a pilot experiment. The probability of presenting the base stimulus as the first or the second in a pair was 0.5 . There was a $500-\mathrm{msec}$ silent period between stimuli, and after each pair there was a 5-sec response interval before presentation of the next pair. The initial step size of $1 \mathrm{msec}$ was halved after the first five reversals. The DL was estimated from the midrun average of 10 reversals with the step of 0.5 msec. Typically, 40 to 60 pairs occurred within each test. Seven DL estimates were collected for each base stimulus (starting with $T=10 \mathrm{msec}$ ) from each subject. The subjects were run individually in approximately $45-\mathrm{min}$ sessions.

Subjects. Four subjects participated in the experiment. Three of them were graduate students in the Sound Engineering Department at the Warsaw Academy of Music. They were aware of the purpose of the test and were paid for their participation. All of them had passed a special course on so-called "timbre solfeggio" (Lętowski, 1985). The first author was the fourth subject.

\section{Results and Discussion}

The mean DL results of the 4 subjects are plotted in Figure 1 for each basic rise-time value. Results for all subjects are very consistent in the 10 - to $30-\mathrm{msec}$ range, with almost constant DL values between 1 and $1.8 \mathrm{msec}$. For $T=40 \mathrm{msec}$, differential thresholds increased quite rapidly, especially for Subject L.K. At $T=60 \mathrm{msec}$, DLs fell again, except for Subject J.S.

The subjects' reports suggested that two different cues were used for discrimination of short and long rise times. For sharp onsets ( $T$ shorter than 30 to $40 \mathrm{msec}$ ) subjects typically listened for the relative amplitude of a thump at the beginning of a stimulus, reflecting spectral splatter of energy. For longer onset times different cues were used, related directly to some percept of time. This cue change probably caused the increase of DLs for $T$ values above $30 \mathrm{msec}$.

If Weber's law were applicable to rise-time discrimination, the $\Delta T$ function should closely approximate a

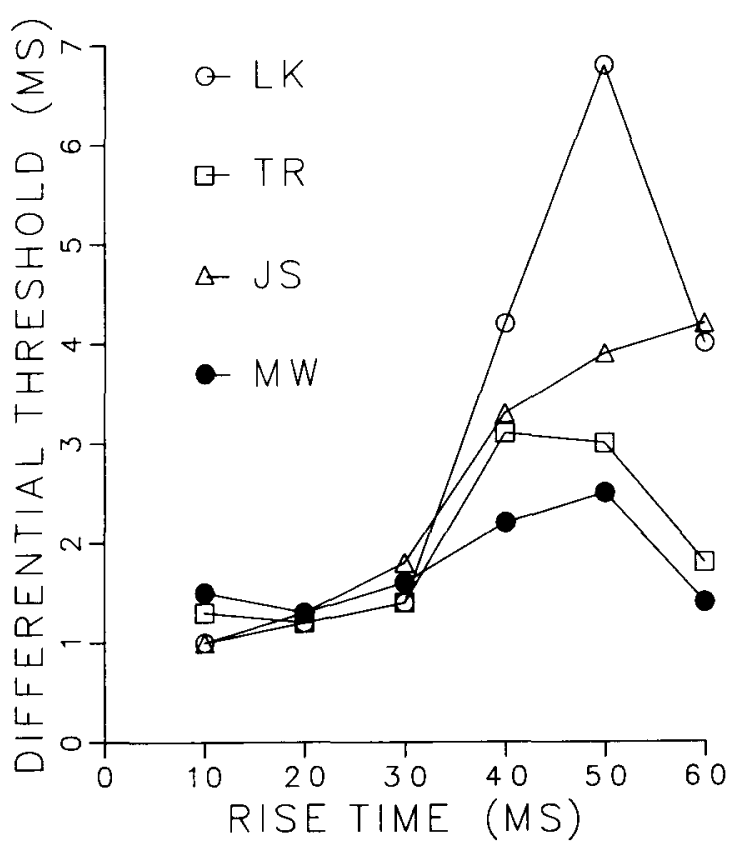

Figure 1. Results of Experiment 1. The mean differential thresholds of rise time versus rise time for the 4 subjects. 
straight line. The averages of the means for our 4 subjects were calculated, and a linear regression was performed in the range $10 \leq T \leq 50 \mathrm{msec}$, where a correlation of $r=0.95$ was obtained. These results are displayed in Figure 2 (filled circles), together with three comparable sets of data found in the literature. The first set is from a study by Van Heuven and Van den Broecke (1979), in which the DL in onset time of a $1000-\mathrm{Hz}$ tone with a steady-state portion of $200 \mathrm{msec}$ and a decay of $50 \mathrm{msec}$ was measured by the method of adjustment for onset times between 10 and $80 \mathrm{msec}$ (open circles). These data also seem to support Weber's law, with a (linear-fit) correlation of $r=0.93$. The second set of data (open squares) is from a later study by the same authors (Van den Broecke $\&$ Van Heuven, 1983), in which they measured onset DLs, also by adjustment, for sound bursts of variable waveform and temporal structure. The results shown here are for a $1000-\mathrm{Hz}$ sine wave with a steady-state plus decay portion of $230 \mathrm{msec}$. Again, up to about 50-msec rise time, the data support Weber's law, with a linear correlation of $r=0.97$, but with a DL size of about 5 msec more than they had found in their previous study. For longer rise times, they obtained almost constant DLs of about $15 \mathrm{msec}$. The third set of data (open triangles) is taken from a study by Kewley-Port and Pisoni (1984), who used $300-\mathrm{Hz}$ sawtooth waves of $1-\mathrm{sec}$ total duration, with the onset ramp followed immediately by a linear decay. Using a discrimination procedure similar to ours, they found that DLs in the range $10 \leq T \leq 80 \mathrm{msec}$, averaged over 4 subjects, supported Weber's law to the extent that a

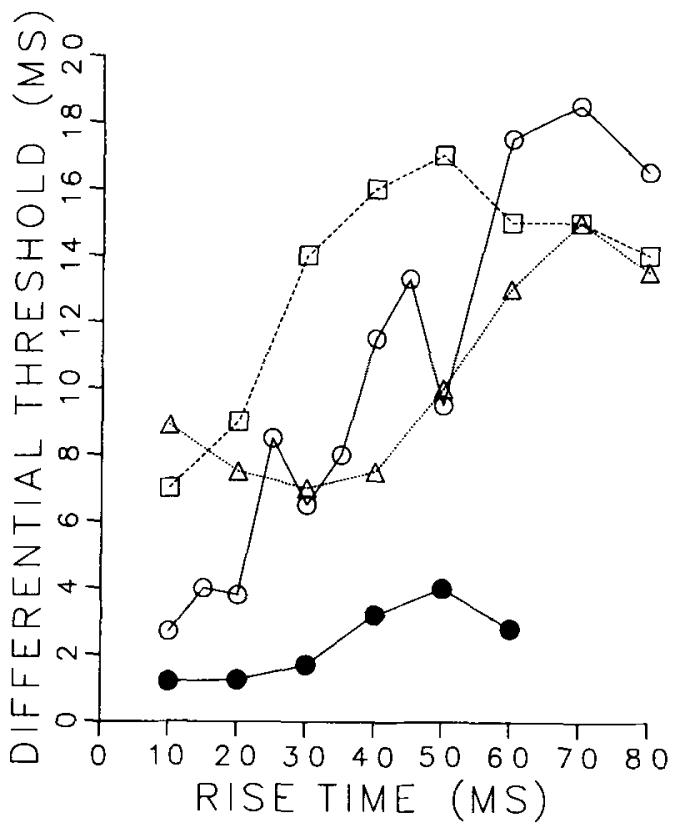

Figure 2. Differential thresholds of rise time versus rise time. Filled circles: the averages of the means for the 4 subjects of Experiment 1. Open circles: data from Van Heuven and Van den Broecke (1979). Squares: data from Van den Broecke and Van Heuven (1983). Triangles: data from Kewley-Port and Pisoni (1984). linear-fit correlation coefficient of 0.88 was obtained. On the whole, we may therefore conclude that onset discrimination for sinusoidal tones seems to be governed by Weber's law, and that there is no evidence of discontinuities that would reflect any form of categorical perception. For well-trained subjects, the Weber fraction $\Delta T / T$ is about $6 \%$ to $8 \%$ for rise times between 10 and $60 \mathrm{msec}$, but for untrained subjects, this Weber fraction may be up to three times as large.

The hypothesis that energy splatter may be a significant perceptual cue in the discrimination of short attacks was investigated in Experiment 2, which is discussed next.

\section{EXPERIMENT 2}

\section{Method}

In this experiment, stimuli again consisted of $1000-\mathrm{Hz}$ pure-tone bursts, with a variable attack, a steady-state portion, and a $40-\mathrm{msec}$ decay, such that the overall stimulus duration was $256 \mathrm{msec}$. For the attack, three onset functions were used in separate blocks of tests: (1) a linear attack, according to the formula

$$
A=k \frac{t}{T}
$$

where $A$ is the envelope amplitude, $T$ is the rise time, and $k$ is a constant; (2) an exponential attack, with

$$
A=k \frac{10}{9}\left(1-10^{-t / T}\right)
$$

where the multiplication by $1 \%$ serves to terminate the amplitude at $t=T$ with the same amplitude as the linear ramp; and (3) a raisedcosine attack, with the rise-time function

$$
A=\frac{k}{2}\left(1-\cos \frac{t}{T} p\right) .
$$

Four stimuli with rise times of $10,20,30$, and $40 \mathrm{msec}$ were the base stimuli around which DLs were measured. The stimuli were synthesized digitally, using a Philips P857 minicomputer and a 12bit D/A converter, at a $10-\mathrm{kHz}$ sampling frequency. They were presented binaurally through TDH-49 headphones with circumaural cushions at $80 \mathrm{~dB}$ SPL in an IAC double-wall chamber. An adaptive two-interval forced-choice task with feedback was used. There was a 3-sec response time limit, and feedback was provided immediately after each response. All other parameters of the test were the same as in Experiment 1.

Five DL estimates were collected for each base stimulus and each subject. The subjects were run individually in approximately 30 min sessions. For each base stimulus, the subjects were tested with linear onset functions and, after having completed five adaptive runs, tested with the exponential and raised-cosine ones.

Three subjects, 2 males and 1 female, participated in the experiment. These included both authors. The third subject was a student of musicology who had no previous experience with systematic listening experiments. She was trained for $4 \mathrm{~h}$ to become familiar with the procedure and with the percept of rise time.

\section{Results and Discussion}

The mean DLs and corresponding standard deviations of the 3 subjects are plotted in Figure 3 for the linear, in Figure 4 for the exponential, and in Figure 5 for the raised-cosine onsets as a function of onset time. The 


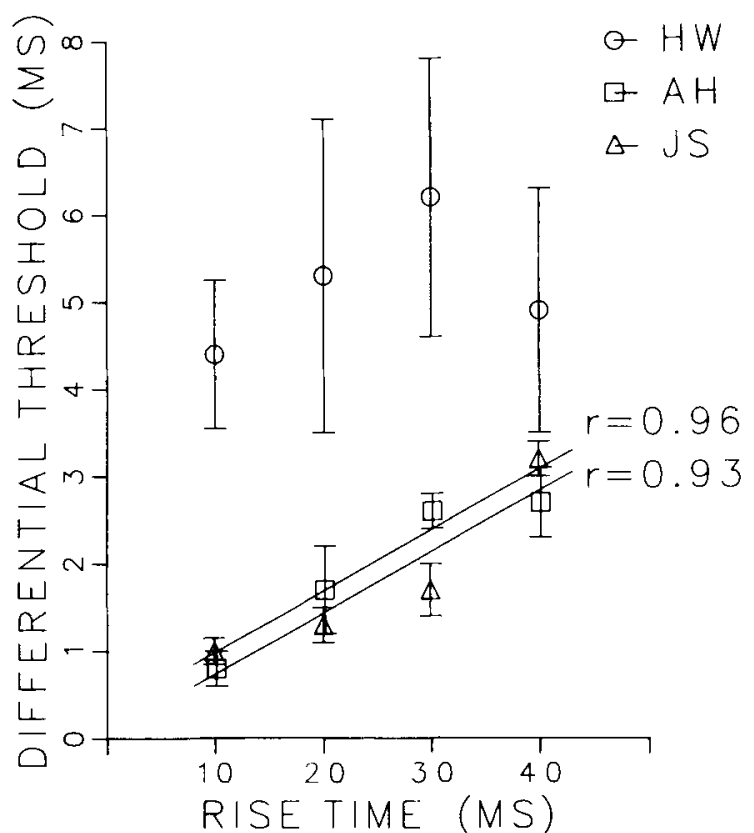

Figure 3. Results of Experiment 2 for linear onset, showing mean differential rise-time thresholds as a function of rise time for the 3 subjects. Vertical bars represent standard deviations. Values of $r$ are correlation coefficients for linear regressions.

results of Subject J.S. for the linear onset are almost identical to his DLs obtained in Experiment 1. This confirms that the small differences between methods of stimulus generation and presentation in the two experiments were not significant.

A global inspection of the results presented in Figures 3,4 , and 5 shows that much larger DLs, and also much larger standard deviations, were obtained from the inexperienced subject $\mathrm{H}$.W. than from the trained subjects A.H. and J.S. For a linear onset, however, the DLs of H.W. are quite comparable to the data of Van Heuven and Van den Broecke (1979) for $T$ values between 10 and $30 \mathrm{msec}$, as can be seen from Figures 2 and 3. H.W.'s threshold at a rise time of $40 \mathrm{msec}$ is also comparable to that of Subject L.K., as can be seen in Figure 1. The DLs of Subject A.H. for a linear attack are in good agreement with the results of Experiment 1 . At $10 \mathrm{msec}$ his performance was better, but for $T=30 \mathrm{msec}$, it was slightly worse than that of the other subjects.

Because the spread of H.W.'s results is so large, a statistical analysis was performed only on the data of Subjects J.S. and A.H. Differential thresholds for each base stimulus were subjected to an analysis of variance of 2 (subjects) $\times 3$ (onset ramps). Significant individual differences $[F(1,24)=16.6, p<.001]$ were found only for $T=\mathbf{4 0} \mathrm{msec}$. The influence of onset ramps was not significant. Interaction effects (subjects $\times$ ramps) occurred at $T=10 \mathrm{msec}[F(2,24)=5.4, p<.025]$ and at $T=$ $30 \mathrm{msec}[F(2,24)=9.9, p<.001]$. Inspection of individual results yielded nonsignificant differences between
DLs for the three onset functions, except at $T=30 \mathrm{msec}$ between the linear and raised-cosine onsets for both subjects $[F(1,24)=9.7, p<.005$, for J.S., and $F(1,24)=$ 8.3, $p<.01$, for A.H.].

For both subjects and all three onset functions, linear regression fits of the $\Delta T$ versus $T$ functions were made. Correlation coefficients between 0.88 and 0.99 were obtained. Because the general shape of empirical discrimination functions suggested nonlinear fits in some cases, tests for linear, quadratic, and cubic trends were performed (Winer, 1971). For Subject A.H., $F$-ratios of linear trend did not exceed the critical value $\left[F_{.99}(2,16)\right.$ $=6.36]$ with any of the three onsets, so the data did not imply significant deviations from linearity. For Subject J.S., the smallest correlation coefficient with a linear fit $(r=0.88)$ was obtained for the exponential onset. In this case, $79 \%$ of the variation in the rise-time DL was accounted for by a linear regression equation and $9 \%$ by a quadratic trend $[F(1,16)=10.65, p<.005]$. A quadratic trend was also reported by Van Heuven and Van den Broecke (1980). The data of Subject J.S. for the linear and raised-cosine onsets did not show significant deviations from linear trend.

\section{GENERAL DISCUSSION}

According to the theory of categorical perception, there should be a rapid change of differential threshold along a rise-time continuum: large DLs for stimuli belonging

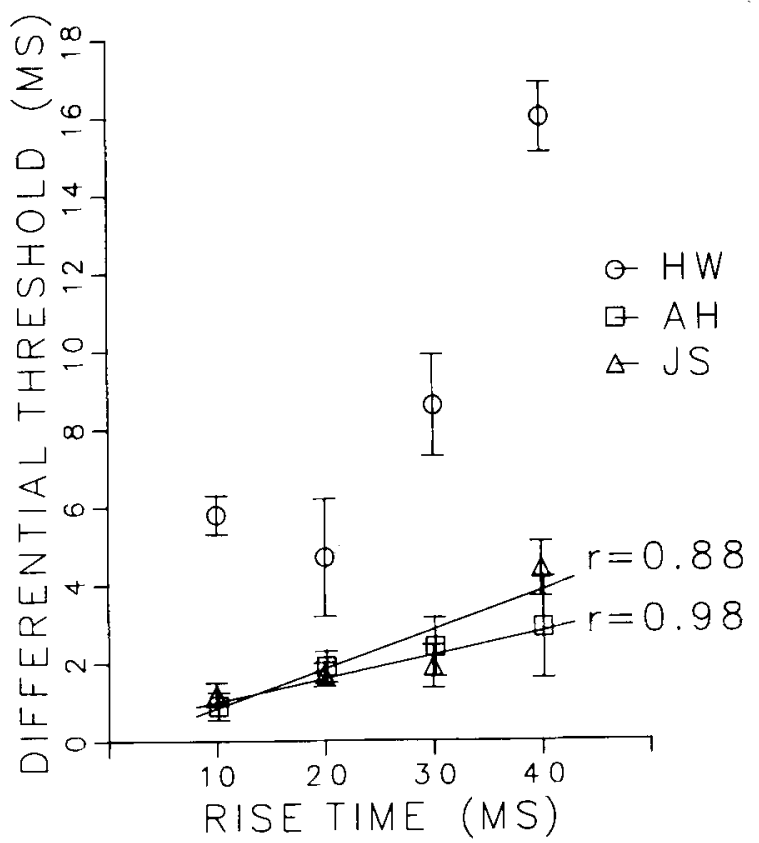

Figure 4. Results of Experiment 2 for exponential onset, showing mean differential rise-time thresholds as a function of rise time for the 3 subjects. Vertical bars represent standard deviations. Values of $r$ are correlation coefficients for linear regressions. 


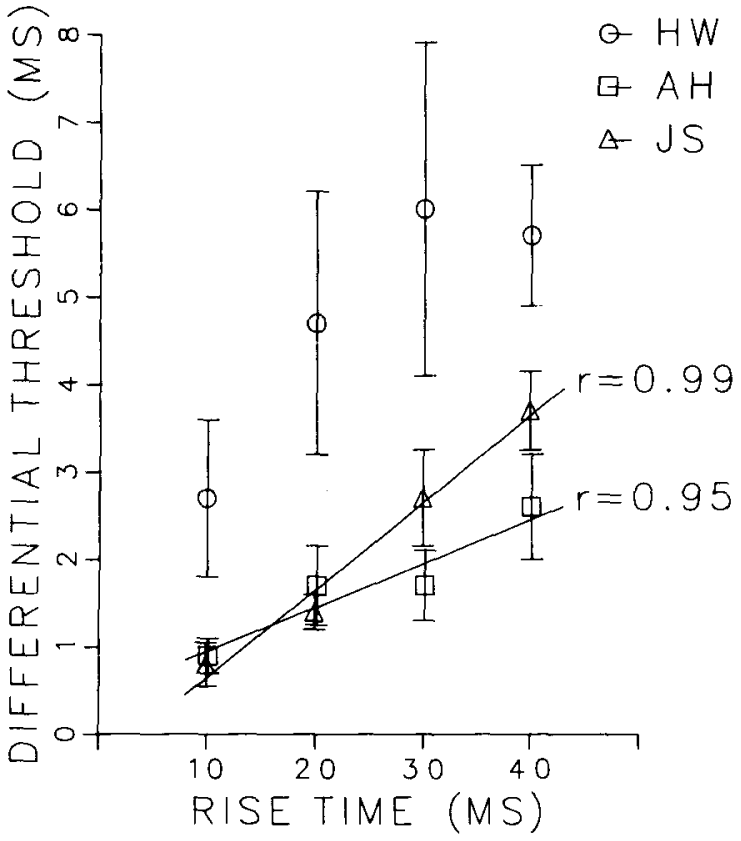

Figure 5. Results of Experiment 2 for raised-cosine onset, showing mean differential rise-time thresholds as a function of rise time for the 3 subjects. Vertical bars represent standard deviations. Values of $r$ are correlation coefincients for linear regressions.

to the same category, and small ones for those from different categories. No support for categorical perception can be found in the discrimination data reported here. In almost all cases, functions of $\Delta T$ versus $T$ can be predicted by linear trend, implying that Weber's law holds for risetime discrimination.

In the few cases in which Weber's law does not seem to hold, for instance with the results of Experiment 1 measured above $40 \mathrm{msec}$, it is much more reasonable to assume that a subjective cue change has taken place along the onset-time continuum, rather than categorical perception. The shape of the DL curves is always such that, with increasing $T$, the DL grows at an accelerated rate beyond some point, but declines again when $T$ is increased further. Such behavior is expected if one perceptual cue gradually disappears with increasing $T$ before a second, different cue has become audible. On the other hand, the shape of the curves shown in Figure 1 are exactly opposite what one would expect if categorical perception had taken place. Our finding that rise time discrimination is most difficult at intermediate values of $T$, somewhere around $\mathbf{4 0}$ or $50 \mathrm{msec}$, is consistent with results obtained by Rosen and Howell (1983), who used $300-\mathrm{Hz}$ sinusoidal bursts and were their own (presumably well-trained) subjects.

Our subjects, as well as those from an earlier study by Rosen and Howell (1981), reported that, for short rise times, they could judge differences between onset slopes by the strength of a thump at the beginning of the stimulus. This may indicate that a perceptual correlate of energy splatter served as the dominant discrimination cue. This hypothesis can be tested by investigating whether there is a stable relationship, taken over the three different onset functions, between amounts of energy splatter away from the signal frequency on the one hand, and discrimination performance on the other. To this end, the Fourier transforms $\mathscr{F}(\omega)$ were calculated for each onset function of Equations 1, 2, and 3. Next, using the modulation theorem (Papoulis, 1962), energy spectra $\varepsilon(\omega)$, according to the equation

$$
\varepsilon(\omega)=\frac{1}{4} \mid \mathscr{F}\left(\omega+\omega_{0}\right)-\mathscr{F}\left(\omega-\omega_{0}\right)^{2},
$$

were obtained for all three onset functions and all risetime values used in Experiment 2, with $\omega_{0}$ set equal to $2000 \pi$. Most of the energy is concentrated at the frequency of the sinusoid (on-frequency energy), namely at $1000 \mathrm{~Hz}$, but some energy falls above and below that frequency (off-frequency energy). The total energy of the onset is proportional to its rise time, but off-frequency energy decreases as rise time increases. An example of two energy spectra, one for a linear onset portion of $T$ $=10 \mathrm{msec}$, the other for an onset with $T+\Delta T=$ $11 \mathrm{msec}$, is shown in Figure 6.

Our hypothesis is that subjects judge rise-time differences as intensity differences in the critical band around the signal frequency. According to the multiband excitation-pattern model of Florentine and Buus (1981), intensity discrimination is based on a weighted sum of observations in all critical bands. Therefore, the energy in critical bands for all three onset functions and all the different rise-time values was calculated. The percentage of total energy in the ninth critical band, corresponding to a frequency band from 920 to $1080 \mathrm{~Hz}$ (Zwicker \&

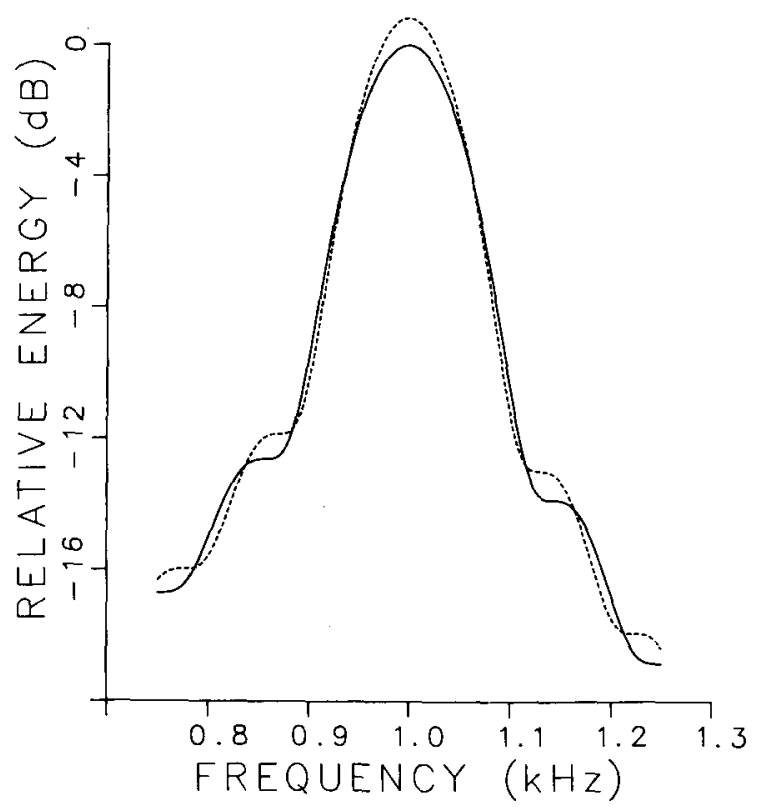

Figure 6. Energy spectra for two linear onset ramps: solid line for $T=10$ msec; dashed line for $T+\Delta T=11$ msec. Energy is expressed in dB re energy at $1000 \mathrm{~Hz}$ for $T=10 \mathrm{msec}$. 

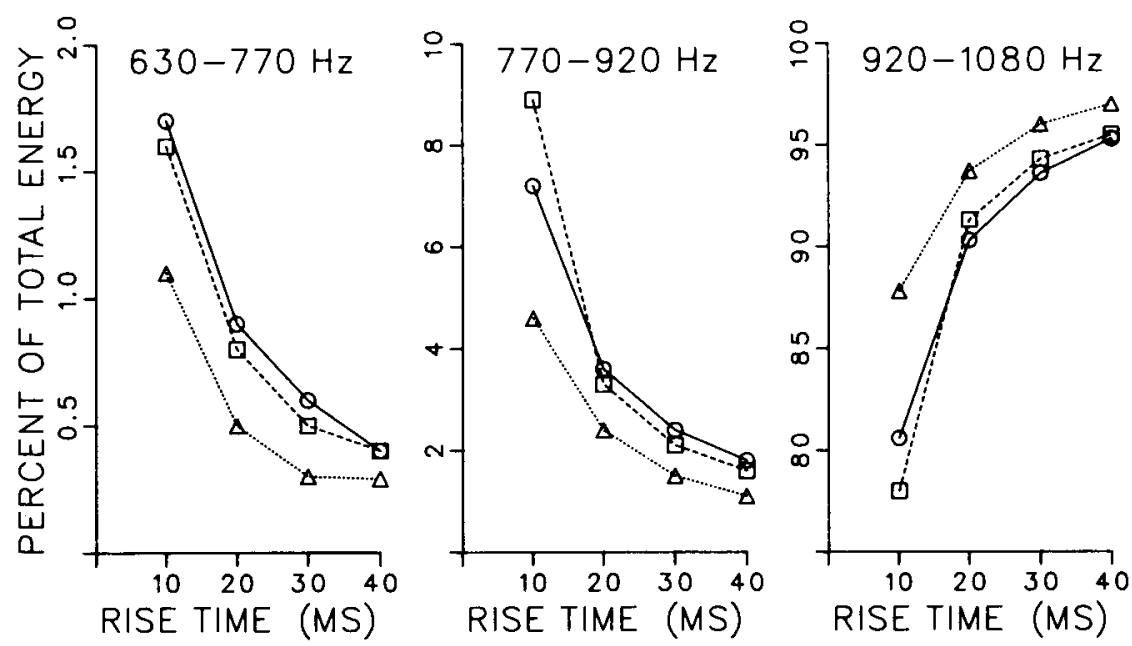

Figure 7. Percent of total energy in the seventh, eighth, and ninth critical bands versus rise time. Circles: linear onset. Triangles: exponential onset. Squares: raised-cosine onset.

Feldtkeller, 1967), increases with rise time, while the relative amount of energy in other critical bands decreases. This is illustrated in Figure 7 for $T=10,20,30$, and $40 \mathrm{msec}$ in the seventh, eighth, and ninth critical bands for all three onset functions used in Experiment 2.

The empirical results of Experiment 2 were transformed in the following manner. The energy in the ninth critical band was calculated for each base stimulus with rise time $T$, yielding the value $E_{s T}$, and for each stimulus with rise time $T+\Delta T$, yielding the value $E_{V}$, where $\Delta T$ is the empirically obtained DL for a particular subject. Then the energy ratio, $E_{V} / E_{S T}$, was converted into decibels by computing

$$
\Delta L=10 \log \frac{E_{V}}{E_{S T}} .
$$

The results of this computation are shown in Table 1. One sees the empirically determined differential thresholds for rise time and the corresponding values of $\Delta L$ for all 3 subjects, all three onset functions, and all four basic onset time values used in the experiment. The table shows that $\Delta L s$ for Subjects A.H. and J.S. are within a range of $0.15 \mathrm{~dB}$ for all three onset functions with the same total rise time. Deviations are larger for Subject H.W., but the results for all onset functions at $T=20$ and $T=30 \mathrm{msec}$ are quite consistent.

Similar $\Delta \mathrm{L}$ calculations were made for the $7 \mathrm{th}, 8$ th, 10 th and 11 th critical bands. For each value of $T$ and $\Delta T$, these $\Delta L s$ were found to be much smaller than their counterparts in the 9th critical band.

$\Delta L s$ for each subject were next averaged over onset ramps and plotted against $T$. This is shown in Figure 8. The procedure mentioned above was also used to calculate $\Delta L s$ from the subject-averaged results of Experiment 1 , which are shown in Figure 8 as well. All these results together exhibit the same general trend and appear quite consistent with one another. The absolute size of the $\Delta L$ s, between 0.3 and $0.7 \mathrm{~dB}$, agree quite well with intensity DLs measured with $1000-\mathrm{Hz}$ tones and welltrained subjects (Jesteadt, Wier, \& Green, 1977; Rabinowitz, Lim, Braida, \& Durlach, 1976).

Our experimental results, transformed into equivalent $\Delta L$ values in the principal critical band, can also be com-

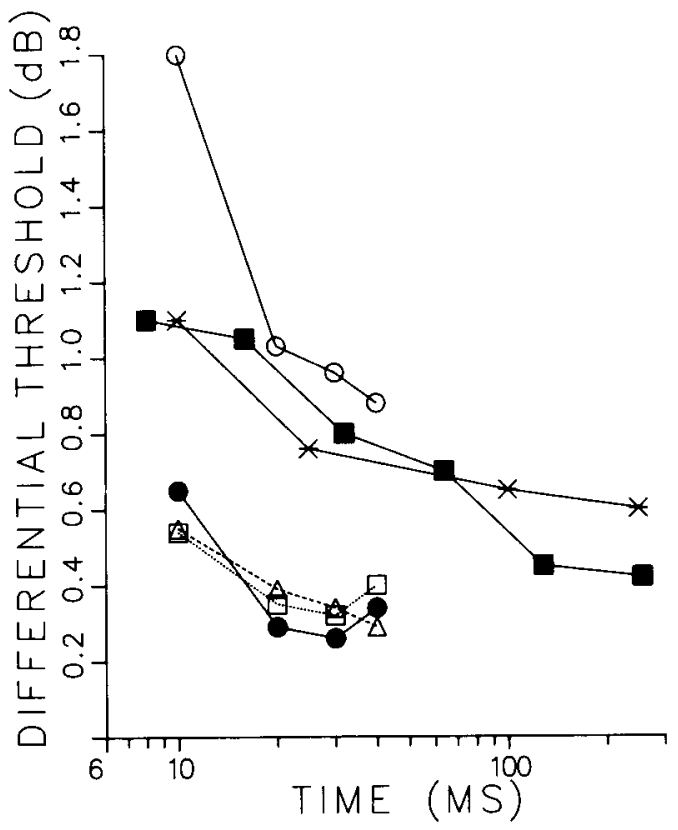

Figure 8. Results of Experiment 1 and Experiment 2 calculated as differential thresholds of intensity in the ninth critical band versus rise time (see text). Filled circles: subject-averaged results of Experiment 1. Open circles: results of Subject H.W. from Experiment 2. Open squares: results of Subject J.S. from Experiment 2. Open triangles: results of Subject A.H. from Experiment 2. Remaining data are intensity difference limens for pure tones versus duration of tone pulses obtained by Henning (1970; crosses) and by Forentine (1986; filled squares). 
Table 1

Onset-Time and Equivalent-Intensity DLs of Experiment 2

\begin{tabular}{|c|c|c|c|c|c|c|c|c|c|c|}
\hline \multirow[b]{2}{*}{$\mathbf{T}$} & & \multicolumn{3}{|c|}{ Subject A.H. } & \multicolumn{3}{|c|}{ Subject J.S. } & \multicolumn{3}{|c|}{ Subject H.W. } \\
\hline & & Lin & Ex & $\mathbf{R}-\mathbf{C}$ & Lin & Ex & R-C & Lin & Ex & R-C \\
\hline 10 & $\begin{array}{l}\Delta T \\
\Delta L\end{array}$ & $\begin{array}{l}0.8 \\
0.50\end{array}$ & $\begin{array}{l}0.9 \\
0.52\end{array}$ & $\begin{array}{l}0.9 \\
0.63\end{array}$ & $\begin{array}{l}1.0 \\
0.54\end{array}$ & $\begin{array}{l}1.2 \\
0.55\end{array}$ & $\begin{array}{l}0.8 \\
0.53\end{array}$ & $\begin{array}{l}4.4 \\
2.0\end{array}$ & $\begin{array}{l}5.8 \\
2.04\end{array}$ & $\begin{array}{l}2.7 \\
1.37\end{array}$ \\
\hline 20 & $\begin{array}{l}\Delta T \\
\Delta L\end{array}$ & $\begin{array}{l}1.7 \\
0.33\end{array}$ & $\begin{array}{l}1.9 \\
0.46\end{array}$ & $\begin{array}{l}1.7 \\
0.36\end{array}$ & $\begin{array}{l}1.3 \\
0.33\end{array}$ & $\begin{array}{l}1.7 \\
0.37\end{array}$ & $\begin{array}{l}1.4 \\
0.34\end{array}$ & $\begin{array}{l}5.3 \\
1.14\end{array}$ & $\begin{array}{l}4.7 \\
0.97\end{array}$ & $\begin{array}{l}4.7 \\
0.97\end{array}$ \\
\hline 30 & $\begin{array}{l}\Delta T \\
\Delta L\end{array}$ & $\begin{array}{l}2.6 \\
0.35\end{array}$ & $\begin{array}{l}2.4 \\
0.33\end{array}$ & $\begin{array}{l}1.7 \\
0.29\end{array}$ & $\begin{array}{l}1.7 \\
0.29\end{array}$ & $\begin{array}{l}1.9 \\
0.30\end{array}$ & $\begin{array}{l}2.7 \\
0.38\end{array}$ & $\begin{array}{l}6.2 \\
0.90\end{array}$ & $\begin{array}{l}8.6 \\
1.14\end{array}$ & $\begin{array}{l}6.0 \\
0.83\end{array}$ \\
\hline 40 & $\begin{array}{l}\Delta T \\
\Delta L \\
\end{array}$ & $\begin{array}{l}2.7 \\
0.28 \\
\end{array}$ & $\begin{array}{l}2.9 \\
0.33 \\
\end{array}$ & $\begin{array}{l}2.6 \\
0.27 \\
\end{array}$ & $\begin{array}{l}3.2 \\
0.33 \\
\end{array}$ & $\begin{array}{l}4.4 \\
0.48 \\
\end{array}$ & $\begin{array}{l}3.7 \\
0.40 \\
\end{array}$ & $\begin{array}{l}4.9 \\
0.53 \\
\end{array}$ & $\begin{array}{c}16.0 \\
1.49 \\
\end{array}$ & $\begin{array}{l}5.7 \\
0.61 \\
\end{array}$ \\
\hline
\end{tabular}

Note-Values of $\Delta T$ are differential thresholds (in milliseconds) obtained by Subjects A.H., J.S., and H.W. for $T=10,20,30$, and $40 \mathrm{msec}$ and linear (Lin), exponential (Ex), and raised-cosine (R-C) onset functions. Values of $\Delta L$ (in decibels) were calculated according to the procedure described in the text.

pared with directly measured intensity DLs for pure tones of short duration. Such experimental data have been reported by Henning (1970) and Florentine (1986), and are also plotted in Figure 8. Both studies included measurements made for $1000-\mathrm{Hz}$ pure tones presented at $85 \mathrm{~dB}$ SPL. Henning's and Florentine's data are in good agreement with each other up to a stimulus duration of $50 \mathrm{msec}$. $\Delta L$ values calculated for our subject $H$.W. also appear consistent with their data in the range $20 \leq T \leq$ $40 \mathrm{msec}$. Our other subjects, in Experiment 1 as well as in Experiment 2, yielded much smaller $\Delta L s$. The general trend, however, is similar. $\Delta L$ decreases quite rapidly when $T$ increases from 10 to $20 \mathrm{msec}$, then decreases much less rapidly or remains rather constant for $T$ values between 20 and $40 \mathrm{msec}$. This is equivalent to the socalled near miss to Weber's law reported in the literature for intensity discrimination of pure tones (Jesteadt et al., 1977).

There are several possible reasons for the differences between our results, shown in Figure 8, and those of Henning (1970) and Florentine (1986). First, two highly experienced subjects participated in our experiment. Their sensitivity to slight changes in all aspects of stimuli could have lowered their $\Delta L s$. Second, our model assumed that only sound power in the critical band around the signal frequency is integrated for the exact duration of the signal onset. From Figures 6 and 7, one can see that variation in onset time not only changes the energy in the main critical band, but also, to some extent, in adjacent bands. Our well-trained subjects could have used such offfrequency cues, which have been well documented in the literature (Leshowitz \& Wightman, 1971), but were ignored in our model.

There are also several reasons why integration in our model was limited to the onset portion of the signal. Subjects, by their own account, seemed to focus their attention on the signal attack and appeared to ignore the remainder of the signal when performing the discrimination task. None of the data in the literature, including the present data, give any reason to believe that the duration of the steady-state signal portion is in any way critical for the outcome of discrimination or absolute identification experiments. Furthermore, if the energy in the main critical band were computed over the duration of the entire signal, the resulting $\Delta L s$ would become unrealistically small, and differences between them and other data, as shown in Figure 8, would end up still larger.

Finally, one might wonder how, in terms of our model, the system knows when to stop integrating the onfrequency power. How does it know when the onset is over and the steady state begins? In principle, of course, this information can be obtained from the off-frequency filters, for instance, by waiting until their outputs fall below a certain threshold level. In reality, however, the system may not be able to always clock the onset time interval perfectly. Especially at very short onset times $(10 \mathrm{msec})$, our data suggest that, indeed, integration may have extended somewhat into the steady-state part of the signal. As a result, the actual $\Delta L \mathrm{~s}$ at $T=10 \mathrm{msec}$ would be smaller than the ones we computed and showed in Table 1 and in Figure 8, bringing them somewhat more in line with the $\Delta L s$ computed for other values of $T$. On the other hand, the larger $\Delta L s$ found for smaller $T$ values may also reflect the near miss to Weber's law which is generally found with discrimination of $1000-\mathrm{Hz}$ pure tones, including in Henning's (1970) and Florentine's (1986) studies. Until further work is done, we have to remain speculative on this point.

\section{REFERENCES}

BERGER, K. W. (1964). Some factors in the recognition of timbre. Journal of the Acoustical Society of America, 36, 1888-1891.

BraIDA, L. D., DURLACH, N. I. (1972). Intensity perception: II. Resolution in one-interval paradigms. Journal of the Acoustical Society of America, 51, 483-502.

Clark, M., Luce, D., Abrams, R., Schlossberg, H., \& Rome, J. (1964). Preliminary experiments on the aural significance of parts of tones of orchestral instruments and on choral tones. Journal of the Audio Engineering Society, 12, 28-31.

Cutring, J. E., \& RosNer, B. S. (1974). Categories and boundaries in speech and music. Perception \& Psychophysics, 16, 564-570.

Durlach, N. I., \& BraIDA, L. D. (1969). Intensity perception: I. Preliminary theory of intensity resolution. Journal of the Acoustical Society of America, 46, 372-383. 
FLorentine, M. (1986). Level discrimination of tones as a function of duration. Joumal of the Acoustical Society of America, 79, 792-798.

Florentine, M., \& BuUs, S. (1981). Excitation pattern model for intensity discrimination. Journal of the Acoustical Society of America, 74, 1375-1379.

GARNER, W. R., HAKe, H. W. (1951). The amount of information in absolute judgments. Psychological Review, 58, 446-459.

HENNING, G. B. (1970). A comparison of the effects of signal duration on frequency and amplitude discrimination. In R. Plomp \& G. F. Smoorenburg (Eds.), Frequency analysis and periodicity detection in hearing (pp. 350-361). Leiden, The Netherlands: Sijthoff.

JesteAdT, W., Wier, C. C., \& GreEN, D. M. (1977). Intensity discrimination as a function of frequency and sensation level. Journal of the Acoustical Society of America, 61, 160-177.

KeWley-PorT, D., \& PISONI, D. B. (1984). Identification and discrimination of rise time: Is it categorical or noncategorical? Journal of the Acoustical Society of America, 75, 1168-1176.

Leshowitz, B., \& WightMan, F. L. (1971). On-frequency masking with continuous sinusoids. Journal of the Acoustical Society of America, 49, 1180-1190.

ŁE,TOWSKI, T. (1985). Development of technical listening skills: Timbre solfeggio. Journal of the Audio Engineering Society, 33, 240-244.

PApouLs, A. (1962). The Fourier integral and its applications. New York: McGraw-Hill.

Rabinowitz, W. M., Lim, J. S., Braida, L. D., \& DURlach, N. I. (1976). Intensity perception: VI. Summary of recent data on deviations from Weber's law for $1000-\mathrm{Hz}$ tone pulses. Journal of the Acoustical Society of America, 59, 1506-1509.
Rosen, S. M., \& Howell, P. (1981). Plucks and bows are not categorically perceived. Perception \& Psychophysics, 30, 156-168.

Rosen, S. M., Howell, P. (1983). Sinusoidal plucks and bows are not categorically perceived, either. Perception \& Psychophysics, 34, 233-236.

Saldanha, E. L., Corso, J. F. (1964). Timbre cues and the identification of musical instruments. Journal of the Acoustical Society of America, 36, 2021-2026.

SMURZYŃSKI, J. (1985). Noncategorical identification of rise time. Perception \& Psychophysics, 38, 540-542.

Van den Broecke, M. P. R., \& Van Heuven, V. J. (1983). Effect and artifact in the auditory discrimination of rise and decay time: Speech and nonspeech. Perception \& Psychophysics, 33, 305-313.

Van Heuven, V. J., Van den Broecke, M. P. R. (1979). Auditory discrimination of rise and decay times in tone and noise bursts. Journal of the Acoustical Society of America, 66, 1308-1315.

Van Heuven, V. J., \& Van den Broecke, M. P. R. (1980). Auditory discrimination of rise and decay times in various speech and nonspeech sounds. Progress Report of the Institute of Phonetics, Utrecht University, 5.1, 22-32.

WINER, B. J. (1971). Statistical principles in experimental design. London: McGraw-Hill.

Zwicker, E. Feldtkeller, R. (1967). Das Ohr als Nachrichtenempfänger. Stuttgart: S. Hirzel Verlag.

(Manuscript received March 25, 1988; revision accepted for publication July 6,1988 .) 